\title{
Intrapulmonary Thymoma
}

National Cancer Institute

\section{Source}

National Cancer Institute. Intrapulmonary Thymoma. NCI Thesaurus. Code C45638.

An epithelial neoplasm that arises from ectopic thymic tissue in the lung. Histologically it is identical to the thymomas that arise from the mediastinum. Signs and symptoms include cough, dyspnea, fever, and weight loss. Surgical excision is the recommended treatment. 